OPEN ACCESS

Edited by:

Robert Weissert,

University of Regensburg, Germany

Reviewed by:

Maria José Sá,

Centro Hospitalar São João, Portugal Moussa Antoine Chalah,

Hôpitaux Universitaires Henri Mondor,

France

${ }^{*}$ Correspondence:

Ingrid van der Mei

ingrid.vandermei@utas.edu.au

Specialty section

This article was submitted to

Multiple Sclerosis and

Neuroimmunology,

a section of the journal

Frontiers in Neurology

Received: 10 February 2018 Accepted: 22 May 2018

Published: 08 June 2018

Citation:

Tao C, Simpson S Jr, Taylor BV Blizzard L, Lucas RM, Ponsonby A-L, Broadley S, AusLong/Ausimmune Investigators Group and van der Mei I (2018) Onset Symptoms, Tobacco Smoking, and Progressive-Onset Phenotype Are Associated With a Delayed Onset of Multiple Sclerosis, and Marijuana Use With an Earlier

Onset. Front. Neurol. 9:418. doi: 10.3389/fneur.2018.00418

\section{Onset Symptoms, Tobacco Smoking, and Progressive-Onset Phenotype Are Associated With a Delayed Onset of Multiple Sclerosis, and Marijuana Use With an Earlier Onset}

Chunrong Tao ${ }^{1}$, Steve Simpson Jr. ${ }^{1,2}$, Bruce V. Taylor ${ }^{1}$, Leigh Blizzard ${ }^{1}$, Robyn M. Lucas ${ }^{3}$, Anne-Louise Ponsonby ${ }^{4}$, Simon Broadley ${ }^{5}$, AusLong/Ausimmune Investigators Group and Ingrid van der Mei ${ }^{1 *}$

\footnotetext{
${ }^{1}$ Menzies Institute for Medical Research, University of Tasmania, Hobart, TAS, Australia, ${ }^{2}$ Institute for Health \& Ageing, Australian Catholic University, Melbourne, VIC, Australia, ${ }^{3}$ National Centre for Epidemiology and Population Health, Canberra, ACT, Australia, ${ }^{4}$ Murdoch Children's Research Institute, University of Melbourne, Melbourne, VIC, Australia, ${ }^{5}$ School of Medicine, Griffith University, Gold Coast, QLD, Australia
}

Background: Age at symptom onset (ASO) is a prognostic factor that could affect the accrual of disability in multiple sclerosis (MS) patients. Some factors are known to influence the risk of multiple sclerosis (MS), but their influence on the ASO is less well-investigated.

Objective: Examine the associations between known or emerging MS risk factors and ASO.

Methods: This was a multicenter study, incident cases $(n=279)$ with first clinical diagnosis of demyelinating event aged 18-59 years recruited at four Australian centres (latitudes $27^{\circ}-43^{\circ} \mathrm{S}$ ), from 1 November 2003 to 31 December 2006. Environmental/behavioral variables and initial symptoms were recorded at baseline interview. Linear regression was used to assess the association between risk factors and ASO.

Results: Five factors were significantly associated with ASO: a history of tobacco smoking was associated with 3.05-years later ASO $(p=0.002)$; a history of marijuana use was associated with 6.03-years earlier ASO ( $p<0.001)$; progressive-onset cases had 5.61-years later ASO ( $p=0.001)$; an initial presentation of bowel \& bladder and cerebral dysfunctional were associated with $3.39(p=0.017)$ and 4.37-years $(p=0.006)$ later $\mathrm{ASO}$, respectively. Other factors, including sex, offspring number, latitude of study site, history of infectious mononucleosis, HLA-DR15 \& HLA-A2 genotype, 25(OH)D levels, and ultraviolet radiation exposure were not associated with ASO. Including all five significant variables into one model explained $12 \%$ of the total variance in ASO. 
Conclusion: We found a novel association between a history of tobacco smoking and later onset, whereas marijuana use was associated with earlier onset. Behavioral factors seem important drivers of MS onset timing although much of the variance remains unexplained.

Keywords: first demyelinating event, age at symptom onset, smoking, offspring number, marijuana, multiple sclerosis

\section{INTRODUCTION}

Multiple sclerosis (MS) is a chronic inflammatory and degenerative disease of the central nervous system (CNS), caused by a complex interplay between genetic and environmental factors (1). HLA-DR15*01 genotype (2), lower vitamin D (3) or exposure to ultraviolet radiation (UVR) (4), tobacco use (5), and past infection with Epstein-Barr virus (6) are the main factors implicated in MS risk. Our group recently demonstrated that these risk factors could explain $63.8 \%$ of the attributable risk (7), with $53.3 \%$ of that due to the environmental factors. Other factors such as HLA-A2 genotype (8) (protective), offspring number (9) (protective), and marijuana use (5) (detrimental), have some evidence of involvement in MS risk.

While a number of studies have examined risk factors for the onset of MS, far fewer have tested associations with age at symptom onset (ASO), which is the age at which first symptoms suggestive of future MS occur. Current studies $(10,11)$ mostly suggest a significant prognostic value of ASO in patients with MS, with an early onset correlated with a benign disease progression. Some studies showed that lower sun exposure in adolescence was associated with earlier ASO $(12,13)$. One cohort study ( $n=895$ cases) found no difference in ASO between never and ever smokers (32.29 and 32.75 years, respectively) (14). One study $(n=816)$ found that cases with HLA-DR15 risk genotype had roughly 2.5-years earlier onset (15), but a later metaanalysis $(n=2,201)$ showed no association (16). The association between HLA-A2 genotype and ASO has also yielded inconsistent findings $(17,18)$. Our group (19) found that progressive-onset patients had $\sim 9$ years later ASO than relapsing-onset patients $(p<0.001)$.

In view of the conflicting evidence presented above, this paper examines the associations between risk factors for MS onset and ASO in a cohort recruited soon after the first clinical diagnosis of CNS demyelination (FCD).

\section{METHODS}

The Ausimmune Study was an Australian multicenter casecontrol study (20). Case participants were aged 18-59 years and resident in a study region: Brisbane city (latitude $27^{\circ}$ South), Newcastle city and surrounds $\left(33^{\circ} \mathrm{S}\right)$, Geelong city and the Western Districts of Victoria $\left(37^{\circ} \mathrm{S}\right)$, or the state of Tasmania $\left(\sim 41-43^{\circ} \mathrm{S}\right)$. Incident cases $(n=282)$ were referred to the study by medical specialists, following a FCD. A study neurologist confirmed the date and symptomatology of the demyelinating event(s) that led to study participation and conducted a full neurologic examination. In subsequent follow-up (AusLong study) (21), 3 cases were confirmed as non-MS, and 19 cases were confirmed as primary-progressive MS (PPMS). Among all 279 cases, 217 had been diagnosed as MS at 5-year review. Among 260 relapsing-onset cases, 219 had their first demyelinating event (FDE) during the study recruitment period (1 Nov 2003 to 31 Dec 2006), with remaining cases having had a prior, previously unrecognized neurological event.

The Ausimmune Study was approved by nine regional Human Research Ethics Committees. All participants gave written informed consent.

\section{Measurements}

Demographic, environmental, behavioral and neurological data were collected by self-reported questionnaire and face-to-face interview. Serum samples and biometric measures were taken at face-to-face interview.

Using the Expanded Disability Status Scale (EDSS), clinical presentation was rated for seven function groups (pyramid, cerebellar, brainstem, sensory, bowel \& bladder, cerebral, and visual) using 6-8 point scales. It was assessed by a neurologist via face-to-face interview at baseline. Questionnaire data collected included: a detailed smoking history of tobacco and marijuana use (ever smoked, current smoking status, age started/stopped smoking, pack-years of cigarette smoking, packyears of marijuana use); history of infectious mononucleosis ("have you ever had glandular fever"); number and age of all live births; and for females only, the age at menarche. Participants completed a personal residence calendar (to assist recall of past events), completing for each year of life from age 6 years the location of residence and leisure time in the sun in summer and winter. With the latitude and longitude of the location, average daily ambient erythemally weighted UVR was calculated for every year of life for each participant (4). For each participant, UVR dose $\left(\mathrm{kJ} / \mathrm{m}^{2}\right)$ was estimated for the relevant periods of life by multiplication of the average hours per day outside in each season by the average UVR for that season, and summed over the relevant years. Annual UVR exposure was assigned by adding the summer and winter UVR dose.

Serum concentrations of $25(\mathrm{OH}) \mathrm{D}$ were measured using liquid chromatography tandem mass spectrometry. Skin reflectance on the buttock was measured using a handheld spectrophotometer (Minolta CM-2500D) to estimate cutaneous melanin density (4). The genotyping of HLA-DR15 (SNP rs9271366) was performed by the SNPline method (KBiosciences, Hoddesdon Herts, UK). The genotyping of HLA-A2 (SNP rs2844821 on Illumina Custom MS Chip) was 
performed by the Hussman Institute for Human Genomics, University of Miami.

\section{Data Management and Analysis}

ASO was calculated by subtracting the date of birth from the date of first symptom onset (as determined by review of data by the study neurologist team). Where only the year of symptom onset was recorded, the onset date was assigned as 15th of June of that year and if only the month was known it was assigned as the 15th of the month [year of FDE was recorded in 27 cases, but the results were robust when these data were omitted from the analysis (data not shown)].

Because 25(OH)D levels vary substantially by season, we deseasonalised 25(OH)D levels in each study center using a sine-cosine function, as described previously (4). The $25(\mathrm{OH}) \mathrm{D}$ level was modeled as both a continuous and categorical variable (using commonly used cut-points, $<50,50-75,>75-100,>100$ $\mathrm{nmol} / \mathrm{L})$.

Due to the non-significant association between the degree of clinical presentation and ASO in patients with each clinical symptom $(p>0.05)$, clinical presentation of the seven function groups were coded as no or yes in our analysis.

Log-binomial regression was used to assess the association between categorical variables. Linear regression was used to assess the association between potential predictors and ASO. We mostly examined risk factors that occurred prior to the initial symptom onset to ensure proper temporality, except $25(\mathrm{OH}) \mathrm{D}$ was measured at the baseline review. For variables that were inherently associated with age (e.g., smoking, UVR exposure, offspring number), we summarized the information prior to a specific age (e.g., 28 years for smoking, 31 years for marijuana and offspring number) and examined the associations with ASO after this age to obtain a less biased estimate. The distribution of ASO was left skewed, and a Box-Cox power transformation was applied to reduce heteroskedasticity and thus satisfy the requirements of linear regression. All coefficients presented in the results were back-transformed to the original scale.

In preliminary analyses, participants in Tasmania had a later ASO than other study centers (mean difference: $3.19,95 \% \mathrm{CI}$ $0.73-5.65, p=0.011$ ). The higher ASO was likely driven by the higher average age of the Tasmanian population, but the collinearity between the population mean age and study center $(r=0.91, p<0.001)$ made adjustment not possible. We therefore divided cases into five-year ASO groups (15-19 years, 20-24 years, 25-29 years, 30-34 years, 35-39 years, 40-44 years, 4549 years, 50-54 years, 55-59 years) in each study center, and standardized the ASO to the age distribution in the whole Australian population. After standardization, ASO (from highest to lowest latitude: $37.2,37.6,37.0 \& 37.2$ years, respectively) was similar in the four different study centers.

In the basic multivariable model, we adjusted for sex, study center, and MS onset type (relapsing vs. progressive onset). For UVR exposure analysis, we did not adjust for study center due to collinearity (latitude and ambient UVR are strongly negatively correlated). We adjusted for buttock melanin density to take natural skin type into consideration. For smoking analyses, we further adjusted for tobacco or marijuana smoking, due to the significant positive correlation $(r=0.40, p<0.001)$.

After the univariable and multivariable analyses of each category of exposures, we built a mutually adjusted model including all significant exposures, and examined the total variance explained by these exposures. The relative contribution of each variable was calculated as the change of the residual sum of squares when comparing the model without the variable with the full model.

We conducted a sensitivity analysis restricted to cases with FDE during the recruitment period and excluding those whose ASO was less certain. We performed another separate analysis restricted to cases who had converted to MS by a 5-year followup, (21) thus excluding cases who may never convert to MS. We were concerned that some associations were the result of an age or cohort effect. To examine this we used the controls ( $n=545)$ and assigned the same ASO of the cases to their age and sex-matched controls. With the Australian Electoral Roll, we randomly selected controls and matched to cases on age (within two years), sex, and study region (60\% participated of those originally contacted). The final case:control matching ratio averaged 1:2 (20). If an association was also observed in controls, then that is likely due to an age or cohort effect.

All statistical analyses were undertaken using Stata/SE 12.1 (College Park, TX).

\section{RESULTS}

The mean ASO for the total cohort was 37.3 years and $76.7 \%$ were females. ASO for those who had converted to MS at 5-year follow-up $(n=217)$ was 37.0 years and for cases with FDE during the recruitment period $(n=219)$ was 36.9 years. All primary analyses were based on all patients with FDE $(n=279)$, and sensitivity analyses including patients had converted to MS at 5year review $(n=217)$ or patients with FDE during recruitment period $(n=219)$ were presented in the last section of result.

\section{Sex, HLA-DR15, HLA-A2 and History of Infectious Mononucleosis}

We found no significant associations between ASO and sex, history of IM, HLA-DR15 genotype, or HLA-A2 genotype (Table 1; Supplementary Table 1).

\section{5(OH)D and UVR Dose}

No seasonal pattern was seen in the association between season of FDE and ASO $(F=0.61, p=0.72)$. There was no association between deseasonalised 25(OH)D level and ASO (Table 1). Time between FDE and 25(OH)D being taken did not modify the association between $25(\mathrm{OH}) \mathrm{D}$ and ASO (pinteractio $n=0.38$ ). Cumulative UVR dose (summer, winter, and combined) within different risk windows (e.g., 5, 10, and 15 years) prior to onset and UVR dose during adolescence (6-15 years) showed no convincing associations with ASO (Table 1; Supplementary Table 2).

\section{Onset Type and Initial Symptoms}

ASO of progressive-onset patients was 5.61-years later than relapsing-onset patients $(p=0.013$ ) (Table 2$)$. There was 
TABLE 1 | Associations between sex, IM history, HLA-DR15 genotype, HLA-A2 genotype, 25(OH)D, UVR exposure and age of symptom onset.

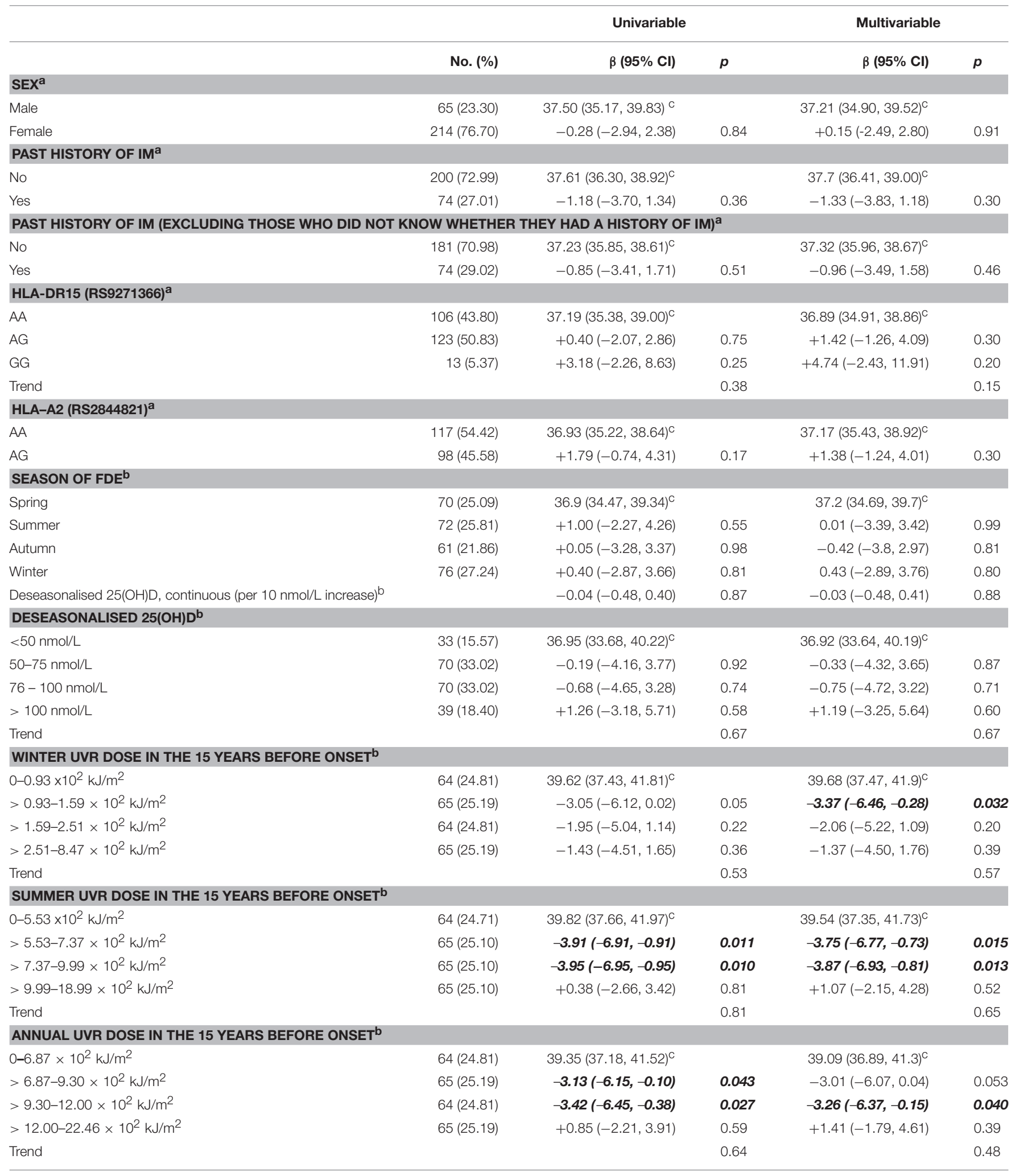

Statistical significance $(p<0.05)$ is denoted in bold and italics.

${ }^{a}$ adjusted for sex, MS onset type and study center; ${ }^{b}$ adjusted for sex, MS onset type and buttock melanin density; ${ }^{c}$ mean ASO of the reference group.

MS, multiple sclerosis; IM, infectious mononucleosis; UVR, ultraviolet radiation; FDE, first demyelinating event. 
TABLE 2 | Associations between onset type and initial symptomatology and age of symptom onset.

\begin{tabular}{|c|c|c|c|c|c|}
\hline & No. (\%) & \multicolumn{2}{|c|}{ Univariable analysis } & \multicolumn{2}{|c|}{ Multivariable analysis $^{a}$} \\
\hline Relapsing-onset & $258(92.47)$ & $36.99(35.84,38.15)^{b}$ & & $36.95(35.8,38.09)^{b}$ & \\
\hline Progressive-onset & $21(7.53)$ & $+4.86(0.44,9.28)$ & 0.031 & +5.61 (1.17, 10.05) & 0.013 \\
\hline \multicolumn{6}{|l|}{ ONSET SYMPTOMS } \\
\hline Pyramidal dysfunction -yes & $107(41.63)$ & $+0.21(-2.17,2.58)$ & 0.86 & $-0.52(-2.94,1.90)$ & 0.67 \\
\hline Cerebellar dysfunction -no & $185(72.27)$ & $36.89(35.53,38.26)^{\mathrm{b}}$ & & $37.01(35.66,38.37)^{\mathrm{b}}$ & \\
\hline Cerebellar dysfunction -yes & $71(27.73)$ & $+2.83(0.24,5.41)$ & 0.032 & $+2.52(-0.08,5.12)$ & 0.06 \\
\hline Brainstem dysfunction -no & 192 (75.59) & $37.43(36.06,38.79)^{\mathrm{b}}$ & & $37.4(36.06,38.75)^{\mathrm{b}}$ & \\
\hline Brainstem dysfunction -yes & $62(24.41)$ & $-0.13(-2.90,2.64)$ & 0.93 & $0.15(-2.59,2.89)$ & 0.92 \\
\hline Sensory dysfunction -no & $114(45.6)$ & $37.6(35.83,39.37)^{\mathrm{b}}$ & & $37.56(35.81,39.3)^{b}$ & \\
\hline Cerebral dysfunction -no & 218 (83.52) & $36.71(35.47,37.95)^{b}$ & & $36.87(35.64,38.1)^{\mathrm{b}}$ & \\
\hline Cerebral dysfunction-yes & $43(16.48)$ & $+5.12(2.08,8.15)$ & 0.001 & +4.37 (1.28, 7.46) & 0.006 \\
\hline Visual dysfunction -no & 178 (70.92) & $37.64(36.25,39.03)^{b}$ & & $37.74(36.38,39.10)^{b}$ & \\
\hline Visual dysfunction -yes & 73 (29.08) & $-0.80(-3.38,1.77)$ & 0.54 & $-1.00(-3.54,1.54)$ & 0.44 \\
\hline \multicolumn{6}{|c|}{ ONSET SYMPTOMS IN RELAPSING-ONSET CASES } \\
\hline Pyramidal dysfunction -no & $147(61.51)$ & $37.22(35.70,38.75)^{b}$ & & $37.35(35.84,38.86)^{b}$ & \\
\hline Pyramidal dysfunction -yes & $92(38.49)$ & $-0.09(-2.55,2.37)$ & 0.94 & $-0.36(-2.80,2.09)$ & 0.77 \\
\hline Cerebellar dysfunction -no & $179(74.27)$ & $36.55(35.18,37.92)^{b}$ & & $36.55(35.19,37.91)^{\mathrm{b}}$ & \\
\hline Cerebellar dysfunction -yes & $62(25.73)$ & $+2.82(0.11,5.52)$ & 0.041 & $+2.91(0.21,5.60)$ & 0.034 \\
\hline Brainstem dysfunction -no & $179(74.9)$ & $36.79(35.39,38.18)^{b}$ & & $36.78(35.41,38.16)^{b}$ & \\
\hline Visual dysfunction -no & $166(70.34)$ & $37.10(35.68,38.51)^{\mathrm{b}}$ & & $37.23(35.83,38.63)^{\mathrm{b}}$ & \\
\hline Visual dysfunction -yes & $70(29.66)$ & $-0.24(-2.84,2.37)$ & 0.86 & $-0.63(-3.22,1.96)$ & 0.63 \\
\hline
\end{tabular}

Statistical significance $(p<0.05)$ is denoted in bold and italics. ${ }^{a}$ adjusted for sex, MS type, and study center; ${ }^{b}$ mean ASO of the reference group.

no association between pyramidal, brainstem, sensory, visual dysfunction and ASO. Cases with bowel/bladder and cerebral symptoms had 3.49 -years $(p=0.017)$ and 4.37 -years $(p=0.006)$ later onset, respectively, persisting on restriction to relapsingonset cases. Patients with cerebellar function impairment had a 2.52-years later onset than those without cerebellar function impairment ( $p=0.057$ ), and this association became significant when restricting to relapsing-onset cases.

\section{Smoking of Tobacco and Marijuana}

Ever smokers had $\sim 5.11$-years later onset than never smokers $(p<0.001)$ (Table 3). The magnitudes were similar between past smokers and current smokers. Cases with an earlier ASO might have had less opportunity to start smoking, so we tested this by only including cases with ASO $\geq 28$ years (as 27 was the oldest age of taking up smoking). While attenuating the magnitude, a history of smoking remained significantly associated with ASO (Table 3). We repeated the analysis in the matched controls, and no difference of ASO was shown (never smokers vs. ever smokers: adjusted $\beta=+0.11$ years, 95\% CI $-1.54-1.77, p=0.89$ ), suggesting the significant association in cases was not due to an age or cohort effect. Among ever smokers, the ASO was similar whether the smoking was taken up early ( $<16$ years) or later ( $p_{\text {interactio }} n=0.26$ ), or the duration was longer or shorter ( $p_{\text {interactio }} n=0.94$ ). Among cases with ASO $\geq 28$ years, total pack years of tobacco use before age 27 was not associated with ASO.

Marijuana use was more common in male cases than in females ( $\mathrm{OR}=0.50, p=0.020$ ), and a history of marijuana use was positively associated with smoking $(\mathrm{OR}=8.05, p<0.001)$. A 
TABLE 3 | Associations between smoking behaviors and age of symptom onset.

\begin{tabular}{|c|c|c|c|c|c|}
\hline & No. (\%) & \multicolumn{2}{|c|}{ Univariable } & \multicolumn{2}{|c|}{ Multivariable $^{a}$} \\
\hline No & $103(37.59)$ & $35.6(33.79,37.41)^{\mathrm{b}}$ & & $34.24(32.41,36.06)^{b}$ & \\
\hline Yes & $171(62.41)$ & $+2.71(0.42,5.00)$ & 0.021 & $+5.11(2.74,7.48)$ & $<0.001$ \\
\hline \multicolumn{6}{|c|}{ SMOKING EVER (ASO $\geq 28$ YEARS) } \\
\hline Yes & $143(64.41)$ & $+1.79(-0.12,3.71)$ & 0.07 & $+3.05(1.16,4.95)$ & 0.002 \\
\hline \multicolumn{6}{|c|}{ SMOKING STATUS } \\
\hline Never smoked & $103(37.59)$ & $35.6(33.78,37.41)^{\mathrm{b}}$ & & $34.21(32.38,36.03)^{b}$ & \\
\hline Past smokers & $101(36.86)$ & $+2.62(0.04,5.20)$ & 0.047 & $+4.80(2.21,7.38)$ & $<0.001$ \\
\hline Current smokers & $70(25.55)$ & $+2.85(-0.01,5.70)$ & 0.05 & $+5.66(2.69,8.64)$ & $<0.001$ \\
\hline Trend & & & 0.037 & & $<0.001$ \\
\hline \multicolumn{6}{|c|}{ SMOKING STATUS (ASO $\geq 28$ YEARS) } \\
\hline Current smokers & $60(27.03)$ & $+1.34(-1.01,3.68)$ & 0.27 & $+3.06(0.65,5.47)$ & 0.013 \\
\hline Trend & & & 0.22 & & 0.010 \\
\hline \multicolumn{6}{|c|}{ AGE UPTAKE SMOKING (ASO $\geq 28$ YEARS) } \\
\hline$\geq 16$ years & $84(58.74)$ & $41.45(39.85,43.05)^{b}$ & & $41.21(39.72,42.7)^{b}$ & \\
\hline$<16$ years & $59(41.26)$ & $-1.77(-4.22,0.68)$ & 0.16 & $-1.35(-3.66,0.97)$ & 0.26 \\
\hline \multicolumn{6}{|c|}{ DURATION OF SMOKING BEFORE AGE 27 (ASO $\geq 28$ YEARS) } \\
\hline$\leq 10$ years & $55(40.44)$ & $40.97(38.99,42.95)^{b}$ & & $40.58(38.67,42.5)^{b}$ & \\
\hline$>10$ years & $81(59.56)$ & $-0.51(-3.07,2.04)$ & 0.69 & $+0.10(-2.40,2.60)$ & 0.94 \\
\hline \multicolumn{6}{|c|}{ TOTAL PACK YEARS OF SMOKING BEFORE AGE 27 (ASO $\geq 28$ YEARS) } \\
\hline 0 & $93(41.33)$ & $39.19(37.77,40.61)$ & & $39.10(37.71,40.49)$ & \\
\hline No & $151(74.02)$ & $41.29(40.24,42.34)^{b}$ & & $41.5(40.43,42.57)^{b}$ & \\
\hline Yes & $53(25.98)$ & $-2.20(-4.14,-0.27)$ & 0.026 & $-2.80(-4.89,-0.71)$ & 0.009 \\
\hline \multicolumn{6}{|c|}{ MARIJUANA STATUS } \\
\hline Never & $190(69.6)$ & $38.58(37.26,39.90)^{b}$ & & $38.56(37.25,39.87)^{b}$ & \\
\hline Past users & $63(23.08)$ & $-4.08(-6.73,-1.43)$ & 0.003 & $-3.98(-6.63,-1.34)$ & 0.003 \\
\hline Current users & $20(7.33)$ & $-3.92(-8.20,0.37)$ & 0.07 & $-3.46(-7.87,0.94)$ & 0.12 \\
\hline Trend & & & 0.003 & & 0.004 \\
\hline \multicolumn{6}{|c|}{ MARIJUANA STATUS (ASO $\geq 31$ YEARS) } \\
\hline Never & $151(74.02)$ & $41.28(40.24,42.33)^{\mathrm{b}}$ & & $41.25(40.22,42.28)^{b}$ & \\
\hline Past users & $39(19.12)$ & $-1.50(-3.71,0.70)$ & 0.18 & $-1.35(-3.58,0.88)$ & 0.24 \\
\hline Current users & $14(6.86)$ & $-4.06(-7.16,-0.95)$ & 0.010 & $-3.88(-7.09,-0.66)$ & 0.018 \\
\hline Trend & & & 0.008 & & 0.016 \\
\hline \multicolumn{6}{|c|}{ TOTAL PACK YEARS OF MARIJUANA USE BEFORE AGE 30 (ASO $\geq 31$ YEARS) } \\
\hline 0 & $180(86.96)$ & $40.96(40.01,41.92)$ & & $40.93(39.99,41.87)$ & \\
\hline $1-30$ & $13(6.28)$ & $+1.13(-2.70,4.96)$ & 0.56 & $+1.48(-2.34,5.30)$ & 0.45 \\
\hline$>30$ & $14(6.76)$ & $-3.16(-6.34,0.02)$ & 0.052 & $-3.07(-6.29,0.14)$ & 0.06 \\
\hline Trend & & & 0.14 & & 0.19 \\
\hline
\end{tabular}

Statistical significance $(p<0.05)$ was denoted in bold and italics. ${ }^{a}$ adjusted for sex, MS type, study centers and tobacco smoking status/marijuana use status; ${ }^{b}$ mean ASO of the reference group. 
history of marijuana use was associated with a 6.03-years earlier ASO (Table 3). The magnitudes were similar between past users and current users. We next evaluated associations among cases with $\mathrm{ASO} \geq 31$ years ( 30 years was the oldest age of taking up marijuana in this cohort). Magnitudes were attenuated but still significant in this subgroup (Table 3). Among cases with ASO $\geq$ 31 years, total pack years of marijuana use before age 30 was not associated with ASO.

\section{Offspring Numbers and Age at Menarche}

Having children was strongly associated with a later ASO (Table 4). The magnitude was potentially biased since those with a later ASO may have had different opportunities to have children. We therefore chose a cut-off point that balanced sample size against the offspring number information, and by restricting to those with ASO $\geq 31$ years, we could include 204 cases and $56.9 \%$ of participant offspring. A significant dose-dependent association remained, albeit with reduced magnitude. This dosedependent association was found in both male and female participants ( $p_{\text {interactio }} n=0.11$ ). When we repeated the analyses in the controls, having more children was also significantly associated with a later ASO (0 vs. $1: \beta=4.55, p<0.001 ; 0$ vs. $\geq 2$ : $\left.\beta=10.41, p<0.001 ; p_{\text {trend }}<0.001\right)$, and restricting to those with ASO $\geq 31$ years still showed a significant association ( 0 vs. 1 : $\beta=1.39, p=0.16$; 0 vs. $\geq 2: \beta=3.48, p<0.001$; $\left.p_{\text {trend }}<0.001\right)$. This suggests that the significant association of offspring number and ASO in cases was largely driven by an age or cohort effect.

The age of the participant when having their first child $(\leq 20$, $21-25,26-30,31-35, \geq 36$ ) was not associated with ASO; the average ASO was around 41 years for each child birth age group. There was no association between age of menarche and ASO $(p=0.27)$.

\section{Mutually Adjusted Model}

We next built a combined model based on the significant findings (tobacco smoking, marijuana use, MS onset type, cerebral dysfunction, and bowel \& bladder dysfunction). The final model explained $\sim 12 \%$ of the total variance in ASO, with marijuana use and tobacco smoking having the largest relative contributions (Table 5).

\section{Sensitivity Analyses}

Sensitivity analyses that restricted to cases with FDE during the study recruitment period or diagnosed MS cases did not materially alter the results (Supplementary Tables).

\section{DISCUSSION}

In this comprehensive study, we systematically evaluated the association between ASO and risk factors for MS onset. A model including all the significant factors explained $12 \%$ of the total variance. Of the individual risk factors, a history of tobacco smoking, progressive-onset type, and cerebral or bowel and bladder symptoms at FDE were associated with a later onset, while marijuana use was associated with an earlier onset. HLA-A2 genotype, HLA-DR15 genotype, latitude of study site, past UVR dose, current $25(\mathrm{OH}) \mathrm{D}$ levels, history of IM, offspring number, age of menarche, and sex were not associated with ASO.

A strength of our study is the detailed information on exposure variables, as well as the study neurologist interview and review of medical records for optimal assessment of the ASO. Also, our findings showed a robustness when repeating the analysis among those diagnosed with MS by 5 -year review (excluding some cases who may not convert to MS), as well as restricting to cases with FDE during the study recruitment

TABLE 4 | Associations between offspring numbers/age at menarche and age of symptom onset.

\begin{tabular}{|c|c|c|c|c|c|}
\hline & \multirow[b]{2}{*}{ No. (\%) } & \multicolumn{2}{|c|}{ Univariable } & \multicolumn{2}{|c|}{ Multivariable } \\
\hline & & $\beta(95 \% \mathrm{Cl})$ & $p$ & $\beta(95 \% \mathrm{Cl})$ & $p$ \\
\hline \multicolumn{6}{|c|}{ OFFSPRING NUMBER ${ }^{a}$} \\
\hline 0 & $111(39.78)$ & $31.16(29.7,32.63)^{\mathrm{C}}$ & & $31.37(29.9,32.83)^{\mathrm{C}}$ & \\
\hline 1 & $39(13.98)$ & +5.97 (3.01, 8.92) & $<0.001$ & $+5.51(2.57,8.44)$ & $<0.001$ \\
\hline 2 or more & $129(46.24)$ & +11.12 (9.06, 13.18) & $<0.001$ & +10.88 (8.84, 12.93) & $<0.001$ \\
\hline Trend & & & $<0.001$ & & $<0.001$ \\
\hline \multicolumn{6}{|c|}{ OFFSPRING NUMBER (ASO $\geq 31$ YEARS) ${ }^{b}$} \\
\hline 0 & $89(43.00)$ & $39.25(37.99,40.5)^{\mathrm{C}}$ & & $39.22(37.99,40.45)^{\mathrm{C}}$ & \\
\hline 1 & $37(17.87)$ & $+1.67(-0.74,4.09)$ & 0.18 & $+1.39(-0.98,3.77)$ & 0.25 \\
\hline 2 or more & $81(39.13)$ & +3.42 (1.47, 5.36) & 0.001 & +3.61 (1.69, 5.54) & $<0.001$ \\
\hline Trend & & & 0.001 & & $<0.001$ \\
\hline \multicolumn{6}{|c|}{ AGE OF MENARCHE ${ }^{a}$} \\
\hline $8-12$ years & $98(46.23)$ & $37.07(35.17,38.97)^{\mathrm{C}}$ & & $37.13(35.24,39.01)^{\mathrm{C}}$ & \\
\hline $13-14$ years & $87(41.04)$ & $+1.13(-1.64,3.9)$ & 0.43 & $+0.98(-1.8,3.75)$ & 0.49 \\
\hline 15-23 years & $27(12.74)$ & $-4.19(-8.24,-0.15)$ & 0.042 & $-3.72(-7.76,0.32)$ & 0.07 \\
\hline Trend & & & 0.22 & & 0.27 \\
\hline
\end{tabular}

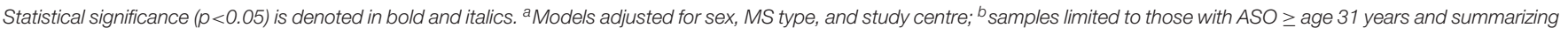
offspring number < age 31 years, models adjusted for sex, MS type, and study centers. ${ }^{C}$ mean ASO of the reference group. 
TABLE 5 | Mutually adjusted model including all factors associated with age of symptom onset.

\begin{tabular}{|c|c|c|c|}
\hline & \multicolumn{3}{|c|}{ All cases (adjusted $R^{2}=0.12$ ) } \\
\hline & $\beta(95 \% \mathrm{Cl})$ & $P$ & RC \\
\hline Smoking status & & & $5.0 \%$ \\
\hline Never smoking & $35.14(33.31,36.98)^{\mathrm{a}}$ & & \\
\hline Past users & +3.80 (1.21, 6.40) & 0.004 & \\
\hline Current users & $+4.72(1.74,7.71)$ & 0.002 & \\
\hline Trend & & 0.001 & \\
\hline Marijuana history & & & $9.2 \%$ \\
\hline Never marijuana & $39.47(38.17,40.78)^{\mathrm{a}}$ & & \\
\hline Past users & $-5.49(-8.29,-2.70)$ & $<0.001$ & \\
\hline Current users & $-7.23(-11.75,-2.71)$ & 0.002 & \\
\hline Trend & & $<0.001$ & \\
\hline MS onset type & & & $0.6 \%$ \\
\hline RRMS & $37.58(36.46,38.69)^{a}$ & & \\
\hline PPMS & $+2.23(-2.05,6.52)$ & 0.31 & \\
\hline Cerebral function & & & $5.9 \%$ \\
\hline No & $36.96(35.78,38.14)^{\mathrm{a}}$ & & \\
\hline Yes & $+4.58(1.68,7.48)$ & 0.002 & \\
\hline Bowel \& bladder function & & & $1.2 \%$ \\
\hline No & $37.3(36.09,38.51)^{\mathrm{a}}$ & & \\
\hline Yes & $+2.13(-0.61,4.87)$ & 0.13 & \\
\hline
\end{tabular}

Statistical significance $(p<0.05)$ is denoted in bold and italics. $R C$, relative contribution. ${ }^{a}$ mean $\mathrm{ASO}$ of the reference group.

period (excluding some whose ASO was slightly less certain). A challenge was that some exposures were intrinsically associated with ASO simply as a function of time. So we assessed the temporal relationship through analyzing some exposure variables before some age points and analyzing the association with ASO after this point. This ensured that the participants included in the analysis had an equal opportunity of exposure, but it substantially reduced the power and assumed that there was nothing unusual about those with a later vs. earlier onset. To examine whether some observed associations were due to an age or cohort effect, we tested whether an effect existed in the age and sex matched controls. Based on that analysis, we believe that the association between offspring number and ASO was not a true association.

In agreement with previous studies $(19,22,23)$, progressiveonset patients showed a later ASO than relapsing-onset patients. In this study, patients with cerebral dysfunction (related to cognition and mood) or bowel and bladder symptoms at FDE had a 4.4 and 3.5 years later ASO, respectively, and cerebellar function impairment (related to ataxia and coordination) was significantly associated with a later onset in relapse-onset patients (2.91 years later ASO). A previous study (24) found no association between psychiatric $(p=0.31)$ or cognitive $(p=0.93)$ symptoms and ASO, but a significant relationship between sphincteric symptoms and ASO $(p=0.012)$. Marked differences in the ASO between that study and presented study ( $\sim 30$ years vs. 37 years) may account for the divergent findings.
The finding that tobacco smoking delayed the average ASO by 4 years is counterintuitive given that it is a risk factor for MS (5). Two other studies have shown a similar directions of effect, with magnitudes of 2.60 years $(n=7,883)(25)$ and 0.82 years $(n=540)(13)$. A null association between tobacco smoking and ASO in healthy controls supported that this association was not due to an age or cohort effect. However, we note that our controls did not show the expected decline in ever smoker status by birth cohort 2004-05 as the general Australian population (26). Some hidden confounder or responder bias, e.g., with older controls being more health conscious and less likely to be smokers may account for this (26). However, the control sample was still a preferable comparison source than the general Australian population, since controls resided in the same regional locations as the cases and were age/sex-matched. The participation rate for controls was lower than cases (20) but this potential volunteer bias would be unlikely to lead to altered patterns of smoking by age among the controls only. A good explanation for the opposite relationship for tobacco use in MS onset $(27)$ versus ASO $(13,25)$ is challenging. It could relate to the anti-inflammatory effects of nicotine upon T-cells, B-cells, and even dendritic cells (28). Tobacco smoking may have a greater impact on neurodegeneration rather than inflammation and immune dysfunction (29) and older onset cases may have a greater neurodegenerative component (30).

Marijuana use was associated with a 6.0-years earlier ASO, despite the Ausimmune Study (5) showing no association between marijuana use and MS risk [never vs. ever, adjusted OR $0.91(0.84-1.54)]$. Other research has demonstrated a detrimental effect of marijuana on the CNS. Two studies $(31,32)$ have showed that marijuana use was associated with poorer cognitive performance in MS patients. Thus, there is some evidence supporting potential deleterious impacts of marijuana use in MS, though the means by which this occurs, requires further study.

Consistent with previous research $(12,13,17,33)$, we found no association between sex, history of infectious mononucleosis, HLA-A2 or HLA-DR15 genotype and ASO. Latitude of study site, deseasonalised 25(OH)D levels and UVR dose were not associated with ASO in the present study. Using the large MSBase global dataset $(n=22,162)$, we previously showed an inverse association between latitude and ASO (every $10^{\circ}$ increase in latitude was associated with a 0.82 -year earlier onset, $p=2.20 \times$ $10^{-13}$ ) (19). However, in line with the present study, subgroup analysis restricting to Australian participants showed a nonsignificant association. Our previous study also found that UVR exposure from age 6 to 15 years and lifetime actinic damage were not associated with ASO (34). Another cross-sectional study (12) $(n=1,161)$ found that vitamin $\mathrm{D}$-associated SNPs and vitamin D supplementation (multivitamin/vitamin D or fatty fish) were not associated with ASO.

While we identified some factors that were associated with ASO, we explained only $12 \%$ of the total variance, thus leaving the majority unexplained. We demonstrated that marijuana use was associated with an earlier MS onset and that a history of tobacco smoking was associated with a later ASO. Further research is required to better understand these opposite effects and underlying pathways. These results, if corroborated and 
supported in other studies, may aid in the understanding of MS and potentially contribute to delaying MS onset.

\section{AUTHOR CONTRIBUTIONS}

CT analyzed the data, wrote the draft manuscript and completed revisions. IvdM designed this study and formulated the hypotheses for this analysis. All authors contributed to data interpretation, critically revised the manuscript for important intellectual content, and read and approved the final manuscript.

\section{FUNDING}

The work was supported by the National Multiple Sclerosis Society of the United States of America (Award RG3364A1/2), the National Health and Medical Research Council of Australia (APP316901 and 224215), the Australian Research Council, The Royal Australasian College of Physicians, the ANZ William Buckland Foundation, Multiple Sclerosis Research Australia and Bayer Schering Pharma and Biogen Idec. Funding sources did not contribute to the design and conduct of the study, management, analysis or interpretation of the data or approval of the manuscript.

\section{AUSIMMUNE/AUSLONG INVESTIGATORS GROUP}

RL (National Centre for Epidemiology and Population Health, Canberra), Keith Dear (Duke Kunshan University, Kunshan, China), A-LP and Terry Dwyer (Murdoch Childrens Research Institute, Melbourne, Australia), IvdM, LB, SS, and BT (Menzies Institute for Medical Research, University of Tasmania, Hobart, Australia), SB (School of Medicine, Griffith University, Gold Coast Campus, Australia), Trevor Kilpatrick (Centre for Neurosciences, Department of Anatomy and Neuroscience, University of Melbourne, Melbourne, Australia). David Williams and Jeanette Lechner-Scott (University of Newcastle, Newcastle, Australia), Cameron Shaw and Caron Chapman (Barwon

\section{REFERENCES}

1. Mechelli R, Annibali V, Ristori G, Vittori D, Coarelli G, Salvetti M. Multiple sclerosis etiology: beyond genes and environment. Exp Rev Clin Immunol. (2010) 6:481-90. doi: 10.1586/eci.10.11

2. Haines JL, Terwedow HA, Burgess K, Pericak-Vance MA, Rimmler JB, Martin ER, et al. Linkage of the MHC to familial multiple sclerosis suggests genetic heterogeneity. The multiple sclerosis genetics group. Hum Mol Genet. (1998) 7:1229-34. doi: 10.1093/hmg/7.8.1229

3. Munger KL, Levin LI, Hollis BW, Howard NS, Ascherio A. Serum 25hydroxyvitamin D levels and risk of multiple sclerosis. JAMA (2006) 296:2832-8. doi: 10.1001/jama.296.23.2832

4. Lucas RM, Ponsonby AL, Dear K, Valery PC, Pender MP, Taylor BV, et al. Sun exposure and vitamin D are independent risk factors for CNS demyelination. Neurology (2011) 76:540-8. doi: 10.1212/WNL.0b013e31820af93d

5. Ponsonby AL, Lucas RM, Dear K, van der Mei I, Taylor B, Chapman $\mathrm{C}$, et al. The physical anthropometry, lifestyle habits and blood pressure of people presenting with a first clinical demyelinating event compared
Health, Geelong, Australia), Alan Coulthard (University of Queensland, Brisbane, Australia), Michael P Pender (The University of Queensland, Brisbane, Australia) and Patricia Valery (QIMR Berghofer Medical Research Institute, Brisbane, Australia).

\section{ACKNOWLEDGMENTS}

We express our heartfelt thanks to the participants in the Ausimmune \& AusLong studies for their time and energy, without which we could not have realized this work.

The authors also thank the paid research personnel, including the local research officers: Susan Agland, BN, Hunter New England Health, Newcastle, New South Wales; Barbara Alexander, BN, Queensland Institute for Medical Research, Queensland; Marcia Davis, MD, Queensland Institute for Medical Research, Queensland; Zoe Dunlop, BN, Barwon Health, Geelong Hospital, Victoria; Rosalie Scott, BN, Royal Brisbane and Women's Hospital, Queensland; Marie Steele, RN, Royal Brisbane and Women's Hospital, Queensland; Catherine Turner, MPH\&TM, Menzies Research Institute, Tasmania; Brenda Wood, RN, Menzies Research Institute, Tasmania; and the Ausimmune Study project officers during the course of the study: Jane Gresham, MA (Int Law), National Centre for Epidemiology and Population Health, The Australian National University, Canberra; Australian Capital Territory; Camilla Jozwick, BSc(Hons), National Centre for Epidemiology and Population Health, The Australian National University, Canberra; Australian Capital Territory; Helen Rodgers, RN, National Centre for Epidemiology and Population Health, The Australian National University, Canberra; Australian Capital Territory.

\section{SUPPLEMENTARY MATERIAL}

The Supplementary Material for this article can be found online at: https://www.frontiersin.org/articles/10.3389/fneur. 2018.00418/full\#supplementary-material

to controls: the Ausimmune study. Mult Scler. (2013) 19:1717-25. doi: $10.1177 / 1352458513483887$

6. Tao C, Simpson S Jr, Taylor BV, van der Mei I. Association between human herpesvirus \& human endogenous retrovirus and MS onset \& progression. J Neurol Sci. (2017) 372:239-49. doi: 10.1016/j.jns.2016. 11.060

7. van der Mei I, Lucas RM, Taylor BV, , Valery PC, Dwyer T, Kilpatrick TJ, et al. Population attributable fractions and joint effects of key risk factors for multiple sclerosis. Mult Scler. (2016) 22:461-9. doi: $10.1177 / 1352458515594040$

8. International Multiple Sclerosis Genetics C, Wellcome Trust Case Control C, Sawcer S, Hellenthal G, Pirinen M, Spencer CC, et al. Genetic risk and a primary role for cell-mediated immune mechanisms in multiple sclerosis. Nature (2011) 476:214-9. doi: 10.1038/nature10251

9. Ponsonby AL, Lucas RM, van der Mei IA, Dear K, Valery PC, Pender MP, et al. Offspring number, pregnancy, and risk of a first clinical demyelinating event: the AusImmune Study. Neurology. (2012) 78:867-74. doi: 10.1212/WNL.0b013e31824c4648 
10. Cierny D, Lehotsky J, Hanysova S, Michalik J, Kantorova E, Sivak S, et al. The age at onset in Multiple Sclerosis is associated with patient's prognosis. Bratisl Lek Listy (2017) 118:374-7. doi: 10.4149/BLL_2017_071

11. Ramachandran S, Strange RC, Jones PW, Kalra S, Nayak D and Hawkins CP. Associations between onset age and disability in multiple sclerosis patients studied using MSSS and a progression model. Mult Scler Relat Disord. (2014) 3:593-9. doi: 10.1016/j.msard.2014.06.002

12. Laursen JH, Sondergaard HB, Sorensen PS, Sellebjerg F and Oturai AB. Association between age at onset of multiple sclerosis and vitamin D level-related factors. Neurology (2016) 86:88-93. doi: 10.1212/WNL.0000000000002075

13. McDowell TY, Amr S, Culpepper WJ, Langenberg P, Royal W, Bever C, et al. Sun exposure, vitamin D and age at disease onset in relapsing multiple sclerosis. Neuroepidemiology (2011) 36:39-45. doi: 10.1159/000322512

14. Manouchehrinia A, Tench CR, Maxted J, Bibani RH, Britton J, Constantinescu CS. Tobacco smoking and disability progression in multiple sclerosis: United Kingdom cohort study. Brain (2013) 136:2298-304. doi: 10.1093/brain/awt139

15. Masterman T, Ligers A, Olsson T, Andersson M, Olerup O and Hillert J. HLADR15 is associated with lower age at onset in multiple sclerosis. Ann Neurol. (2000) 48:211-9. doi: 10.1002/1531-8249(200008)48:2<211::AID-ANA11>3. $0 . \mathrm{CO} ; 2-\mathrm{R}$

16. Barcellos LF, Sawcer S, Ramsay PP, Baranzini SE, Thomson G, Briggs F, et al. Heterogeneity at the HLA-DRB1 locus and risk for multiple sclerosis. Hum Mol Genet. (2006) 15:2813-24. doi: 10.1093/hmg/ddl223

17. Smestad C, Brynedal B, Jonasdottir G, Lorentzen AR, Masterman T, Åkesson E, et al. The impact of HLA-A and -DRB1 on age at onset, disease course and severity in Scandinavian multiple sclerosis patients. Eur J Neurol. (2007) 14:835-40. doi: 10.1111/j.1468-1331.2007. 01825.x

18. Moutsianas L, Jostins L, Beecham AH, 2, Dilthey AT, Xifara DK, Ban M, et al. Class II HLA interactions modulate genetic risk for multiple sclerosis. Nat Genet. (2015) 47:1107-13. doi: 10.1038/ng.3395

19. Tao C, Simpson S Jr., van der Mei I, Blizzard L, Havrdova E, Horakova $\mathrm{D}$, et al. Higher latitude is significantly associated with an earlier age of disease onset in multiple sclerosis. J Neurol Neurosurg Psychiatry (2016) 87:1343-9. doi: 10.1136/jnnp-2016-314013

20. Lucas R, Ponsonby AL, McMichael A, van der Mei I, Chapman C, Coulthard A, et al. Observational analytic studies in multiple sclerosis: controlling bias through study design and conduct. The Australian multicentre study of environment and immune function. Mult Scler. (2007) 13:827-39. doi: $10.1177 / 1352458507077174$

21. Pan G, Simpson S Jr, van der Mei I, Charlesworth JC, Lucas R, Ponsonby A$\mathrm{L}$, et al. Role of genetic susceptibility variants in predicting clinical course in multiple sclerosis: a cohort study. J Neurol Neurosurg Psychiatry (2016) 87:1204-11. doi: 10.1136/jnnp-2016-313722

22. Stankoff B, Mrejen S, Tourbah A, Fontaine B, Lyon-Caen O, Lubetzki C, et al. Age at onset determines the occurrence of the progressive phase of multiple sclerosis. Neurology (2007) 68:779-81. doi: 10.1212/01.wnl.0000256732.36565.4a
23. Confavreux C and Vukusic S. Natural history of multiple sclerosis: a unifying concept. Brain (2006) 129:606-16. doi: 10.1093/brain/awl007

24. Cossburn M, Ingram G, Hirst C, Ben-Shlomo Y, Pickersgill TP and Robertson NP. Age at onset as a determinant of presenting phenotype and initial relapse recovery in multiple sclerosis. Mult Scler. (2012) 18:45-54. doi: $10.1177 / 1352458511417479$

25. Hedstrom AK, Hillert J, Olsson $\mathrm{T}$ and Alfredsson L. Smoking and multiple sclerosis susceptibility. Eur J Epidemiol. (2013) 28:867-74. doi: 10.1007/s10654-013-9853-4

26. NHS 2004-05. Available online at: http://www.abs.gov.au/ausstats/abs@.nsf/ $\mathrm{mf} / 4831.0 .55 .001$ (Accessed 2016-2017)

27. Hedstrom AK, Hillert J, Olsson T, Alfredsson L. Nicotine might have a protective effect in the etiology of multiple sclerosis. Mult Scler. (2013) 19:1009-13. doi: 10.1177/1352458512471879

28. Filippini P, Cesario A, Fini M, Locatelli F, Rutella S. The Yin and Yang of nonneuronal alpha7-nicotinic receptors in inflammation and autoimmunity. Curr Drug Targets (2012) 13:644-55. doi: 10.2174/138945012800399008

29. Pittas F, Ponsonby AL, van der Mei IA, et al. Smoking is associated with progressive disease course and increased progression in clinical disability in a prospective cohort of people with multiple sclerosis. J Neurol. (2009) 256:577-85. doi: 10.1007/s00415-009-0120-2

30. Leray E, Yaouanq J, Le Page E, Coustans M, Laplaud D, Oger J, et al. Evidence for a two-stage disability progression in multiple sclerosis. Brain (2010) 133:1900-13. doi: 10.1093/brain/awq076

31. Honarmand K, Tierney MC, O'Connor P, Feinstein A. Effects of cannabis on cognitive function in patients with multiple sclerosis. Neurology (2011) 76:1153-60. doi: 10.1212/WNL.0b013e318212ab0c

32. Pavisian B, MacIntosh BJ, Szilagyi G, Staines RW, O'Connor P, Feinstein A. Effects of cannabis on cognition in patients with MS: a psychometric and MRI study. Neurology (2014) 82:1879-87. doi: 10.1212/WNL.0000000000000446

33. Wu JS, Qiu W, Castley A, Mastaglia FL, Christiansen FT, Christiansen WM, et al. Modifying effects of HLA-DRB1 allele interactions on age at onset of multiple sclerosis in Western Australia. Mult Scler. (2010) 16:15-20. doi: $10.1177 / 1352458509350312$

34. van der Mei IA, Ponsonby AL, Dwyer T, Blizzard L, Simmons R, Taylor BV, et al. Past exposure to sun, skin phenotype, and risk of multiple sclerosis: case-control study. BMJ (2003) 327:316. doi: 10.1136/bmj.327.7410.316

Conflict of Interest Statement: The authors declare that the research was conducted in the absence of any commercial or financial relationships that could be construed as a potential conflict of interest.

Copyright (C) 2018 Tao, Simpson, Taylor, Blizzard, Lucas, Ponsonby, Broadley, AusLong/Ausimmune Investigators Group and van der Mei. This is an open-access article distributed under the terms of the Creative Commons Attribution License (CC $B Y)$. The use, distribution or reproduction in other forums is permitted, provided the original author(s) and the copyright owner are credited and that the original publication in this journal is cited, in accordance with accepted academic practice. No use, distribution or reproduction is permitted which does not comply with these terms. 